\title{
COLLECTIVE LEARNING IN A LEARNING ORGANIZATION: GROWING TEAM LEARNING CULTURE TO SURVIVE AND DEVELOP
}

\author{
Adi Suryani
}

\begin{abstract}
A learning organization has a deep culture of learning. It is constantly encourage its member to learn. This learning activity is not only for adapting to the rapid changing of its internal and external environment, but also for growing. The effort of a learning organization to create a conducive learning climate can be indicated by training its members. Working towards a learning organization has both its strengths and drawbacks. The strengths are it can improve the organization performance and organization survival. However, learning too rapid can lead to learning stress. Moreover it can lead to harsh internal competition.
\end{abstract}

Keywords: learning, learning organization, training, collective learning, learning culture, learning stress, deep learning, self-managed learning.

Every individual should learn if he/she wants to survive and develop. Organization, which is consisting of groups of individual, should also learn if it wants to not only survive but also to go forward and grow. To respond to the changing of its internal and external environments, competition with other organizations, and threat of potential crises, an unlearning organization can turn itself into a learning organization and even accelerate its capacity to learn. The slow learning organization may also become quick learning organization. Then, what is meant by a learning organization? "A learning organization is an organization that is continually expanding its capacity to create its future." (Senge, 1990, cited in Steiner, 1998, p. 193).

Today's organizations have to face more intense competition. It is not sufficient for an organization to only respond and adapt to the present change. It should continuously scan the changing environment and improve their capacity and maximize their constant learning. The members' learning is expected to improve the organization outcome. Thus, a learning organization is a desirable construct to improve the organizations' performance.

jsh Jurnal Sosial Humaniora, Vol 5 No.2, November 2012 
In this article, I will discuss some aspects of literature in learning organization. I divide the discussion in this essay into 3 parts. The first part is the discussion on the importance and relevance of learning in organization. The second is the discussion on essential parts in the learning organization construct. The last is discussion on the drawbacks and problems arise in learning organization.

\section{The Importance of Learning Culture in a Learning Organization}

Learning organization bears obvious relevance to learning culture. It creates and develops organizational habits which encourage all parts of organization to continuously learn together.

A learning organization has deep learning culture. As noted by Mc.Gill and Slocum (1993, p. 76) a learning organization has three sets of culture that can encourage continuous learning, those are: willingness to learn from the experience, readiness to learn through risk-taking, and determination to learn from mistakes.

Learning from mistakes is one of some learning characteristics of a learning organization. As noted by Mc Gill and Slocum (1993, p. 67) learning organization always introspects itself, be aware of its weakness, and actively examines its environment. A learning organization takes into account its experience and the way it faces and solves based on its experiences (Mc. Gill and Slocum, 1993, p. 73). Moreover, by learning from experience, the organization can get feedback to make organization's decision among alternatives (March and Olsen, 1975, p 148).

Competition can be the source of learning. Learning from competition and understanding its competitor is the other characteristic of a learning organisation. Levitt and March (1988, pp. 331-332) note that based on the ecological effect of learning, how well a certain organization can learn depends on how well it can learn from its own organization, how well it also can learn from its competitors, how well it can process information using technology, and how many competitors it has. Moreover, Kofman and Senge (1993, pp. 8-9) reinforce that learning from 
competition can stimulate change and innovation. The most important thing from learning from competitor's experience is acknowledging when the organization has to compete and when it has to cooperate.

A learning organization demands a learning community to commit to undergo organizational change and to learn. As noted by Kofman and Senge (1993, pp. 5-6) building a learning organization is about building communities of commitment. Moreover, without a collective learning, a learning organization will not learn. Isaacs (1993, p. 28) note that the most obvious problem in a learning organization appears when some people in the organization are willing to learn, while others are satisfy with what they already had. To be a learning organization, the member of organization should demonstrate strong commitment to learn through collecting information, processing, and using the information. Moreover, McGill and Slocum (1993, p. 74) mention that the success of a learning organization comes from its members' commitment to learn from the experience.

One of many ways to grow learning commitment is by frequently involving organizational members in organizational dialogue. As mentioned by Schein (1993, p. 42) a dialogue is the primary format that can facilitate problem solving in group. By engaging a dialogue, trust and commitment can be built. Moreover, dialogue can teach how to learn together as a group. As stated by Isaacs (1993, pp. 26-27) dialogue can encourage people to think together in order to analyze problem that their organization faces, to acknowledge the source of the problem, and to build shared meaning and action in order to solve the problem.

The model below indicates that learning is not only the matter of thinking. Learning always need social context. A learner needs others. Collective learning needs cooperation and share with others. Thus, learning involves systems thinking which covers tools and body of knowledge which have been developed before, personal mastery which encourage learner to be committed to perform lifelong learning by continuously heightening their personal vision, using and concentrating their energy effectively, being patient, and perceiving reality objectively (Senge, 2006, p. 7). 


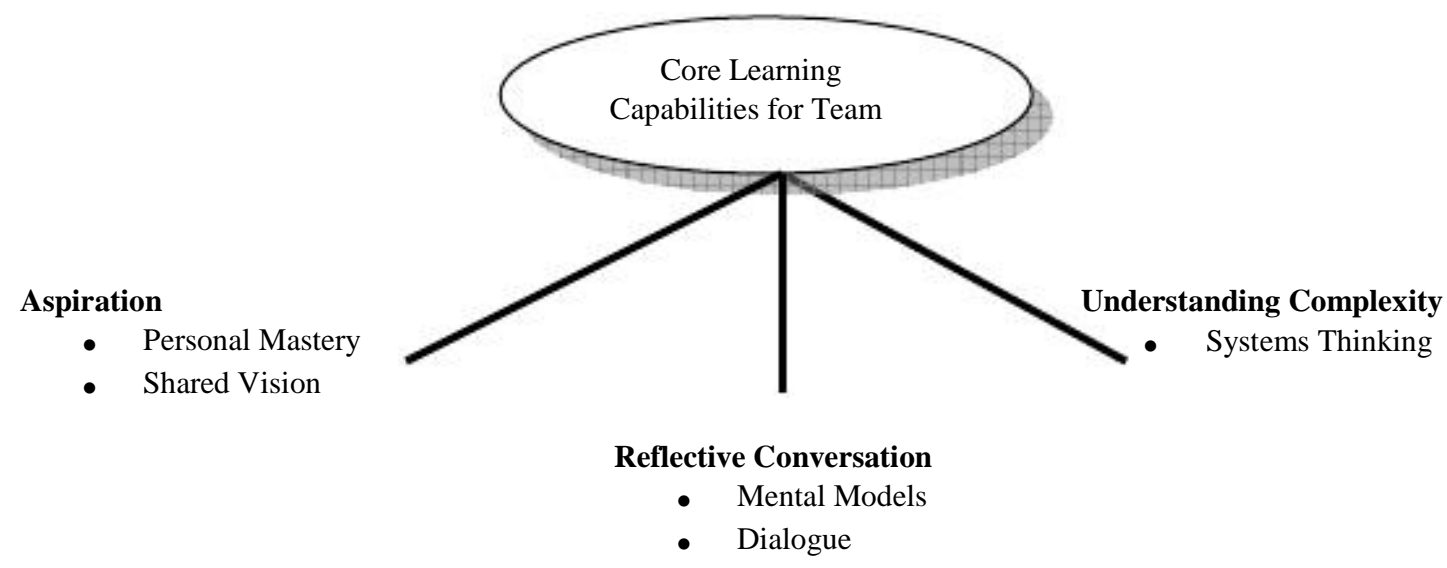

Senge, 2006

This learning process does not happen only internally within a team, but team members should learn from their external environment, from other team. As stated by Senge (2006, p. 219) one of three vital dimensions if learning team is the willingness of other team to cooperate and assist other teams. Senge (2006, p. 218) mentions that team learning itself is a process to improve the capability of team. This needs commitment, shared vision, and skilful members. Moreover the success of learning team depends on three factors, those are: the capacity of each members, the willingness to share knowledge, and willingness to cooperate with other teams (Argote and Brooks, 2005, p. 869). Therefore, learning communities can be build by engaging in collective conversation, cooperate with other people, partnering and building relationship across sectors, and working with 'different' people (Senge, 2006, pp. 307-312).

\section{Deep Learning and Sharing}

Deep learning does not mean that someone can do something just once. Performing deep learning means that someone can do something continuously even by producing higher degree of quality. Deep learning needs learner to pay attention on not only on the thinking process itself but also on external factors which may affect thinking process.

The model below indicates that learning may occur in two levels. The first level indicates that learning involves assessments and results of learning and 
organizational action. Learning may occur in deeper level by involving five components. Those are beliefs and assumptions, practices, skill capabilities, relationships and awareness and sensibilities (Senge, 2006, pp. 284-285)

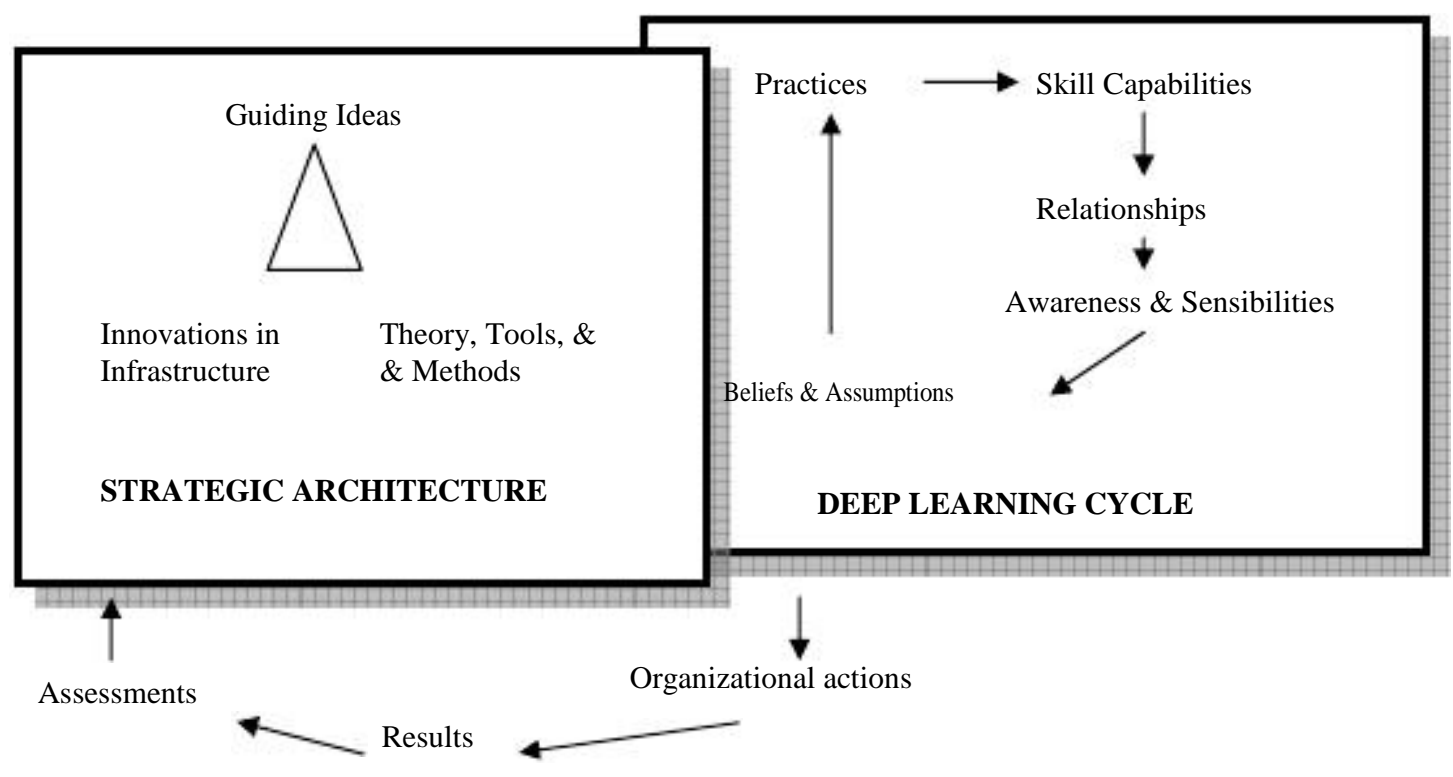

(Senge, 2006, p. 284)

\section{Can an Organization Which Trains its People be Labelled as a Learning Organization?}

An organization which trains its people can be considered as a learning organization apart from whether the training followed brings about some real advantages for the organization or not. This is based on some reasons.

Firstly, training itself is one of many ways to learn. As defined by Tharenou (2001, p. 2) training is planned activity to improve the knowledge and skill of the employees which in turn brings about the improvement in the performance of organization. The organization can train its employees for various reasons. Haccoun et.al (1998, p. 35) note there are three main purposes for training the employees: upgrading the existing skills of the employees, introducing and developing new skills, or altering a certain kind of work behaviour. Continuous training can result on the improvement on the productivity of teamwork, organization's outcome and financial outcome (Tharenou, 2001, pp. 
2-3). Training can also improve the employees' motivation and commitment to work (Rainbird, 1994, cited in Heyes and Stuart, 1996, p. 7). Thus, training can motivate and help the employee or member of organizations to learn. This learning outcome can be used to improve the performance of the learning organization. Most of all, training can improve the self-efficacy of the employees. As contended by Haucoon et. al (1998, p. 33) training can increase the selfefficacy of the employees to learn. Thus, training plays an important role in learning organization since it can encourage employees' motivation to learn, commitment, improve skills, and redirect the employees to have desirable work behaviour.

Secondly, by providing work training for its employees, the organization demonstrates its support for its member to learn and provide conducive environment for the employees to learn. As stated by Argyris and Schon (cited in Kim, 1993, pp. 40-41)the learning in the learning organization is directly or indirectly influenced by the learning outcome of its members. Thus, the effective training can exert significant effects on individual level and organization level. On the individual level, training can improve the skills acquisition of the employees, which collectively can improve the organization performance (Tharenou, 2001, p. 3). As mentioned by Appelbaum and Gallagher (2000, pp. 40-41) the individual skill and knowledge is the asset of organization. However, the organization should decide which knowledge the organization needs and should be developed by the members.

\section{Self-managed Learning, Collective Learning and Training}

Training is one of some modes of collective learning, moreover it needs a collaboration between all of the participants and the organizations (Lynton \& Pareek, 1967. p. 10). There are some trends in training which starts to encourage organizational members to be self-managed learner. There are more and more organizations are more focusing their employees' training skill on self-learning and self- management skills. Galagan (as cited in Cacioppe, Warren-Langford, \& Bell, 1990, p. 65) believe that there are some trends in training and development 
that will persist in the next ten years. One of those trends is instead of teaching some specific job-related skills, the organizations tend to train their employees how to learn, process information, and develop themselves. This is very crucial since the organizations will not be able to provide development program and training for all of their employees all the whole times.

This may due to the enormous amount of the training cost and the financial condition of the organization. Moreover there is an assumption that adults can learn independently. As argued by Kochan and Barocci (1985, p. 193) that different from children who tend to badly need others' help in their learning process, adult tend to be more independent. The skill of self-managing learning is crucial since it can greatly help the employees to face and adapt to changes. Abbott and Dahmus (1992, p. 50) point out that "a rapidly changing high-tech society requires greater emphasis on self-managed learning skills and activities." Moreover, self-managed learning can grow self-motivation to learn. Thus, the most important skill that the organizations should include in their training and development program is skill on how to learn, process information, and implement what they have learnt in their job. The organizations also need to give clear framework of skills and knowledge needed in those organizations.

The other trend is there is a tendency in some organizations to let the employees decide what kind of training they need. Marshall (as cited in Nankervis, Compton, \& Baird, 2005, pp. 295-296) reported that there are 1700 business industries in Australia conduct training in their organizations based on their employees decision. They believe that their employees know the best. Thus, each individual and each sector are given an opportunity to decide what training they will undergo. This strategy has both positive and negative impacts. Positively, this strategy will actively involve the employees in decision making. As proposed by Hosie (1992, p. 61) that self-directed learning realizes that each employees has his/her own style of learning. Addressing this will improve the employees' active participation in the overall learning of organization. Since each individual/sector can decide what training they want to have, there will be many different small-scale training within one organization. This can bring about 
problem in training cost. As articulated by Hosie (1992, p. 59) one of some reasons using technology, such as using satellite technology in delivering training is the organization can conduct training in a large-scale. This can save money. Thus, it can be inferred that conducting many different types of training in smallscale will increase an enormous budget allocation for training and development program.

To be effective, there are three stages that should be included in training: pre-training, training, and post-training phases (Lynton \& Pareek, 1967, pp. 1926). The pre-training phase covers the activity for growing training needs and motivation for the employees. The training phase includes performing training for certain period of time. The post-training is for evaluating the result of training. Dessler, Griffiths, and Lloyd-walker (2004, pp. 313-314) that to see whether the skill taught in training is implemented in the job, there should be further evaluation on the training outcome.

\section{U-Process in Team Learning}

The U-Process of team learning indicates that learning always involve others in team learning. It is started with sensing by building mental models, building personal and shared vision, and engaging in a team learning.

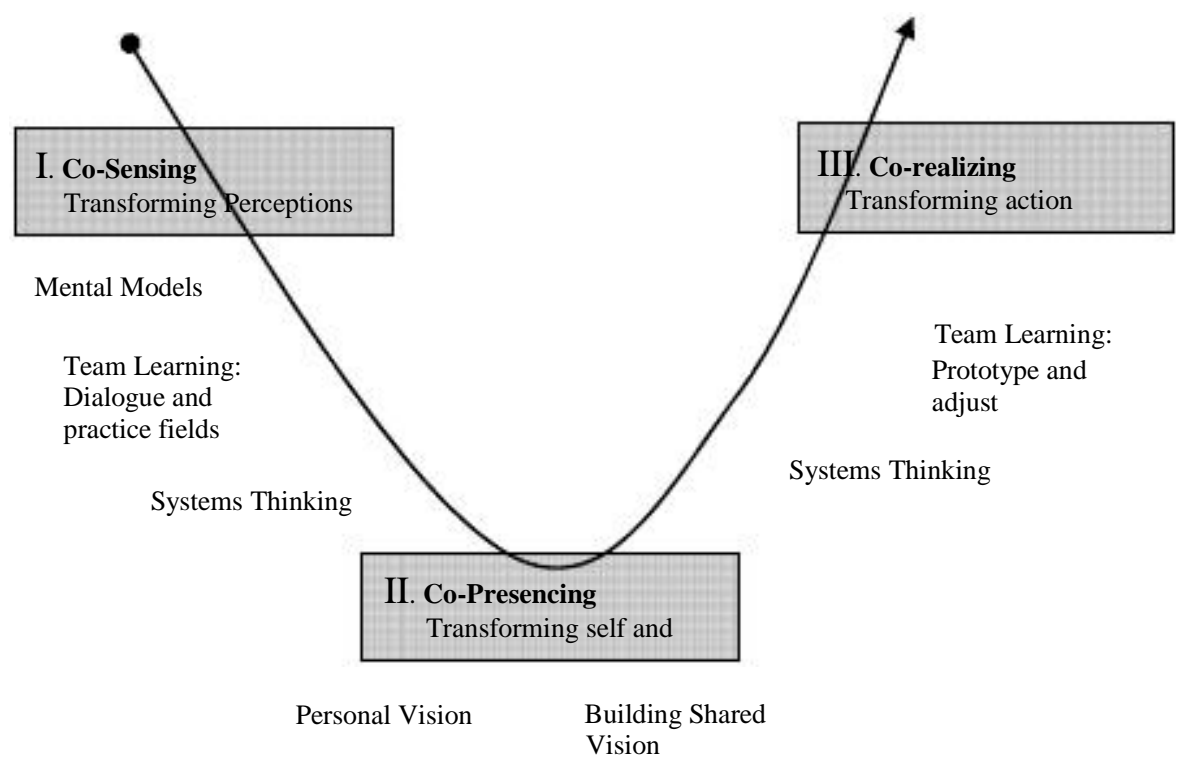

(Senge, 2006, p. 403) 
As noted by Senge (2006, p. 401) "the U-Process helps a group collaboratively undertake sensing: deep inquiry into their mental models through seeing reality beyond their filters, presencing: moving from there to a deep process of connecting with purpose and visioning, individually and collectively, and realizing: then moving into rapid prototyping to translate visions into concrete working models from which feedback can be garnered and further adjustment made. “

The U-Process in team learning also indicates that in learning there will be time for being silent, listening to others, learning together with others, emerging, creating the new, and sharpening learning visions.

\section{Some Drawbacks of Collective Learning in Learning Organization}

Learning can be fun or painful. The learning activity can be painful and stressful if the members of the organization are forced to learn. This is because to keep with the rapid changing of the environment, the organization demands them to learn many new skills faster. This can create learning and working stress. As noted by McHugh and Marie (1993, p. 18) the changing environment and the increasing competition can increase learning pressures which can cause employees' stress. Moreover, Lehersvita (2004, p. 94) states that an employees can learn better if only the new information which they have to learn has relations with their past experiences and skills. The learning stress of the employees can have bad consequences on the organization productivity. The employees suffer from learning stress can frequently absent from work. Moreover, the employees' high absenteeism can reduce the performance of organization. Work stress can directly or indirectly reduce the organization profitability (McHugh et. al, 1993, p. 17). Thus, a learning organization which demands its members to learn too rapid can become stressful organization, if it does not implement effective stress management.

Secondly, learning gap can not be avoided. This gap is caused by two sources. Firstly, not all the members will pro learning, some of them will maintain their status quo. Maintaining status quo can lead to certainty and stability, while 
learning new things can lead to uncertainty, failure and pain (Schein, 1993, p. 87). This can create resistance to change and learning activity. This resistance is the root of conflict in which the resistant member has different self-interest from the organization interest (Waddell and Sohal, 1998, pp. 3-4). Secondly, some members can learn faster and better than others. This can create internal competition. The uncontrolled internal competition can be detrimental. It is destructive when the member of group/the team wants to show their superiority over others, avoid introspecting and admitting his/her weakness, and refusing to share knowledge and cooperate. As contended by Kofman and Senge (1993, p. 9) in competition the member tend to show how good he/she is and conceal his/her weakness. This can impede the process of learning since the essence of learning is admitting the weakness and working on it. Thus, working towards a learning organization can have obvious shortcoming in creating organization instability and leading to internal conflict.

\section{Conclusion}

A learning organization has a deep culture of learning from its past experiment, competitors, and risk-taking. It constantly creates a conducive learning climate for all its members to learn. One of many ways to promote its members to learn is collaborative learning. Learning is both individual and social activity. Learners cannot learn by themselves. They always need others, social context to support them in learning. One form of collaborative learning is through training. Through training the members of the organization can improve the members' existing skills, acquire new knowledge, improve the members' self efficacy, and alter specific work behaviour towards desirable work behaviour. Thus, with its continuous learning, a learning organization can survive and grow. In spite of its strengths, a learning organization also has potential drawbacks. Rapid learning demand as a response to rapid change can create learning frustration and work stress. This can Moreover, different speed in learning can create learning gap. 


\section{References}

Abbott, J., \& Dahmus, S. 1992. Assessing the appropriateness of self-managed learning. The Journal of Management Development, 11 (1), 50-60.

Appelbaum, S., H. \& Gallagher, J. 2000. The competitive advantage of organizational learning. Journal of Workplace Learning, 12 (2), 40-54.

Cacioppe, R., Warren-Langford, P., \& Bell, L. 1990. Trends in human resource development and training. Asia Pacific HRM, 28(2), 55-72.

Dessler, G., Griffiths, J., \& Lloyd-walker, B. 2004. Human Resource Management (2nd ed.). NSW: Pearson Education Australia.

Hacooun et. al. 1998. Training in the 21 st century: Some lessons from the last one. Canadian Psychology, 39 (1/2), 33.

Heyes, J., \& Stuart, M. 1996. Does Training Matter? Employee experiences and attitudes. Human Resource Management Journal, 6 (3), 7-21.

Hosie, P., J. 1992. Human resource managers and training: a peek into the future. Asia Pacific Journal of Human Resources, 30 (3), 49-66.

Isaacs, W., N. 1993. Taking flight: Dialogue, collective thinking, and organizational learning. Organizational Dynamics, Autumn, 24-39.

Kochan, T., A. \& barocci, T., A. 1985. Human resource management and industrial relations. Text, readings, and cases. USA: Scott, Foresman and Company.

Kofman, F. \& Senge P., M. 1993. Communities of commitment: The heart of learning organizations. Organizational Dynamics, Autumn, 5-12.

Kim, D., H. (1993). The link between individual and organizational learning. Sloan Management Review, Fall, 37-50.

Lehesvirta, T. 2004. Learning process in a work organization: From individual to collective and/ or vice versa. Journal of Workplace Learning, 16 (1/2), 92100.

Levitt, B. \& March, J., G. 1988. Organizational learning. Annual Reviews Sociology, 14, 319-340.

Lynton, R., P. \& Pareek, U. 1967. Training for development. Illionis: The Dorsey Press. 
March, J., G. \& Olsen, J., P. 1975. The uncertainty of the past: Organizational learning under ambiguity. European Journal of Political Research, 3, 147171.

McGill, M., E. \& Slocum, J., W. 1993. Unlearning the organization. Organizational Dynamics, Autumn, 67-79.

McHugh \& Marie 1993. Stress at work: Do managers really count the costs? Employee Relations, 15 (1), 18-32.

Mc.Hugh et. al. 1993. Managing work stress: A key issue for all organization members. Employee Counselling Today, 5 (1), 16-21.

Nankervis, A., Compton, R., \& Baird, M. 2005. Human resource management. Strategies and processes (5th ed.). Ohio: South-Western Publishing, Co.

Reagans, R \& Argote, L. \& Brooks, D. 2005. Individual experience and experience working together: Predicting learning rate from knowing who knows what and knowing how to work together. Management Science, 51 (6), 869-881.

Reardon, R., F. 2004. Informal learning after organizational change. Journal of Workplace Learning, 16 (7/8), 385-395.

Senge, P., M. 2006. The Fifth Discipline. The Art \& Practice of The Learning Organisation. Sydney: Random House Australia (Pty) Limited.

Steiner, L. 1998. Organizational dilemma as barriers to learning. The Learning Organization, 5 (4), 193.

Schein, E., H. 1993. On dialogue, culture and organizational learning. Organizational Dynamics, Autumn, 40-51. 
